ARTIGOS / ARTICLES

\title{
Epistemologias do Sul e Transformative Consumer Research: existe um caminho para discutir as linhas abissais em estudos da área de marketing?
}

\section{Epistemologies of the South and Transformative Consumer Research: is there a way to discuss the abyssal lines in marketing studies?}

\author{
Marina Dias de Faria ${ }^{1}$
}

Resumo

\begin{abstract}
A Transformative Consumer Research busca trazer para a área de marketing a visão de que devem ser realizados estudos com o objetivo de proporcionar bem-estar para os consumidores e não somente de gerar resultados para as organizações. Dentro dessa proposta tem-se como base o reconhecimento da existência de relações de poder desiguais entre as pessoas e, portanto, surge um ponto de contato com as premissas das Epistemologias do Sul (Santos, 2018). Segundo Boaventura de Sousa Santos, o capitalismo, o colonialismo e o patriarcado são capazes de criar linhas abissais que separam, sem perspectiva de volta, o "nós" do "eles". Diante das possibilidades de gerar conhecimento agregando-se a discussão das linhas abissais nas pesquisas com perspectiva transformativa, o presente estudo teórico teve como objetivo analisar criticamente a Transformative Consumer Research com base nos conceitos das Epistemologias do Sul. Como resultado desta análise elaborou-se um quadro com 18 pontos que carecem de atenção por parte dos pesquisadores da área de marketing. Tais pontos, nascidos de levantamento teórico, são os principais resultados e contribuições do presente artigo.
\end{abstract}

Palavras-chave: Transformative Consumer Research; Epistemologias do Sul; Linhas abissais.

\begin{abstract}
Transformative Consumer Research seeks to bring to the marketing area the view that studies should be carried out in order to provide well-being to consumers and not only to generate results for organizations. Within this proposal, it is based on the recognition of the existence of unequal power relations between people and, therefore, a point of contact arises with the premises of
\end{abstract}

\footnotetext{
${ }^{1}$ Pós-doutorado pelo Centro de Estudos Sociais da Universidade de Coimbra (CES-UC), Coimbra, Portugal. Professora da Universidade Federal do Rio de Janeiro (UFRJ), Rio de Janeiro, Rio de Janeiro, Brasil. E-mail: marinafaria86@hotmail.com
} 
the Epistemologies of the South (Santos, 2018). According to Boaventura de Sousa Santos, capitalism, colonialism and patriarchy are capable of creating abyssal lines that separate, without prospect of return, the "we" from the "they". Given the possibilities of generating knowledge by adding the discussion of the abyssal lines in research with a transformative perspective, the present study aimed to critically analyze Transformative Consumer Research based on the concepts of the Epistemologies of the South. As a result of this analysis, a table was created with 18 points that need attention from marketing researchers. Such points, from the theoretical survey, are the main results and contributions of this article.

Keywords: Transformative Consumer Research; Epistemologies of the South; Abyssal lines.

\section{Introdução}

A proposta de debate lançada neste ensaio teórico parte da afirmação base feita por Mick (2006) de que a adoção do paradigma transformativo em marketing representa o primeiro passo para que a pesquisa do consumidor comece a pautar-se também para o benefício e para o bem-estar do ser humano, e não somente das empresas. Esta busca pelo bem-estar, principalmente dos consumidores vulneráveis, está atrelada à visão emancipatória dos participantes, ou seja, buscando formas para promover modificações na pessoa e/ou no meio em que ela se insere (DAVIS; OZANNE; HILL, 2016). Em estudo sobre a produção de pesquisadores brasileiros de pesquisas alinhadas à Transformative Consumer Research (doravante TCR) entre 2005 e 2018, Almeida et al. (2018) apontam para a necessidade de que mais esforços sejam feitos para que o conhecimento na área de marketing realmente avance no sentido das propostas da perspectiva transformativa.

Diante dessas afirmações fica claro que, apesar de se colocar como uma perspectiva menos instrumental do que se apresenta como hegemônico em marketing, a TCR ainda está longe de ser (se é que um dia será) uma efetiva mudança na base epistêmica dos estudos da área. Neste sentido, o presente ensaio parte de algumas inquietações: "quem são os seres humanos que podem se beneficiar das pesquisas alinhadas à TCR?"; "realmente interessa aos acadêmicos de marketing produzir pesquisas que proporcionem meios para aumentar o bem-estar dos consumidores?"; "a quem pode incomodar as pesquisas alinhadas à TCR?"; "as metodologias tradicionalmente utilizadas na área de marketing são capazes de fato de promover estudos em linha com a perspectiva transformativa?".

No mesmo sentido, ao buscar esse questionamento sobre as possibilidades de se promover discussões mais diversas e que reconheçam outras formas de conhecimento em marketing chega-se à proposta de ecologia dos saberes. Tal ecologia, segundo as Epistemologias do Sul, trataria a valorização de todas as formas de conhecimento, sem invisibilizar ou descredenciar formas de saber (SANTOS; CARVALHO-FREITAS, 2018). Com tal reflexão acrescenta-se mais uma pergunta norteadora às já apresentadas no parágrafo anterior: "na academia de administração existe espaço para discussões das Epistemologias do Sul?". Aqui, neste artigo, não se tem a pretensão de responder a todos estes questionamentos; busca-se somente instigar os pesquisadores da área a pensarem sobre estes pontos ao mesmo tempo em que se propõe que se faça este caminho por meio das Epistemologias do Sul cunhadas por Boaventura de Sousa Santos. Dentro desta proposta definiu-se, então, como objetivo principal do estudo analisar criticamente a Transformative Consumer Research com base nos conceitos das Epistemologias do Sul.

As Epistemologias do Sul desafiam as epistemologias dominantes uma vez que se concentram em conhecimentos considerados inexistentes por não serem produzidos de acordo com metodologias aceitáveis ou porque são produzidos por sujeitos ausentes, sujeitos concebidos como incapazes de produzir conhecimento válido devido à sua falta de 
preparo ou mesmo à sua condição não plenamente humana. Estes indivíduos são nomeadamente os que sofrem opressões causadas pelo capitalismo, pelo colonialismo e pelo (hetero) patriarcado. De acordo com Boaventura de Sousa Santos, estas são as formas de opressão capazes de criar linhas abissais, que separam o humano do sub-humano (SANTOS; CARVALHO-FREITAS, 2018).

Acredita-se que é exatamente por questionarem a não existência de alguns indivíduos que têm sua vivência marcada pela exclusão que as Epistemologias do Sul podem ser um caminho importante para analisar criticamente as pesquisas alinhadas à TCR. Fundamental lembrar que a ontologia da perspectiva transformativa prevê a existência de múltiplas realidades que são socialmente construídas. Existe, assim, a certeza de que certos indivíduos ocupam uma posição de maior poder e a exclusão social pode vir de privilégios indevidos (MERTENS, 2007). Ao buscar entender esses privilégios indevidos como advindos principalmente das opressões do capitalismo, do colonialismo e do patriarcado a presente pesquisa traz indicações de caminhos críticos que podem se beneficiar das importantes discussões já realizadas nas Ciências Sociais acerca de exclusões abissais, lutas de resistência e metodologias pós-abissais (SANTOS, 2002; 2007; 2018).

O presente artigo está estruturado em mais cinco seções além desta introdução. Na próxima seção são apresentados de forma breve alguns conceitos fundamentais da Transformative Consumer Research. Esta apresentação serve de base para iniciar alguns questionamentos sobre o que é preconizado pela TCR, questionamentos estes que surgem quando se escolhe os caminhos epistêmicos propostos por Boaventura de Sousa Santos. A terceira seção, também de forma sucinta, destinase exatamente a apresentar as bases das Epistemologias do Sul. Não se tem de forma alguma a intenção de aprofundar o levantamento teórico da TCR e das Epistemologias do Sul, uma vez que se acredita que os pesquisadores dispostos a realizar pesquisas nestes caminhos terão que buscar conhecimento em livros seminais e em artigos recentes exaustivamente a fim de dar conta da profundidade das duas propostas. Na seção quatro são resgatadas questões da literatura sobre os ditos "consumidores vulneráveis", uma vez que se acredita que são estes os que podem se beneficiar com estudos verdadeiramente alinhados com a perspectiva transformativa e com base nas Epistemologias do Sul. A primeira e mais importante modificação é trazer os conhecimentos destes grupos e reconhecer seu protagonismo em suas lutas. Cabe o destaque antecipado que o correto, do ponto de vista das Epistemologias do Sul, seria utilizar o termo "consumidores vulnerabilizados”. A quinta seção apresenta um convite para pensar a exclusão na sociedade de consumo sob a perspectiva das Epistemologias do Sul; tem-se neste momento o foco principalmente nas opressões decorrentes da lógica capitalista. Destaca-se, entretanto, que não somente o capitalismo, mas também o colonialismo e o patriarcado, apontados por Boaventura de Sousa Santos como capazes de promover exclusões abissais, devem ser alvo de investigações realmente críticas em marketing. $\mathrm{O}$ intuito ao levantar os aspectos relativos ao capitalismo foi somente elaborar um pouco mais o caminho inicial que pode ser seguido tendo como base questões da sociedade de consumo amplamente conhecidas por pesquisadores de administração. A última seção traz as considerações finais e a proposta de 18 pontos para serem analisados com base nas Epistemologias do Sul nas pesquisas que se utilizam da TCR.

\section{Tranformative Consumer Research: conceitos principais e discussões recentes}

Para Mick (2006), o bem-estar do ser humano deve ser central na preocupação de pesquisadores que adotam o paradigma transformativo em estudos envolvendo consumo. Ozanne (2011) faz um apelo por novas pesquisas ancoradas no paradigma transformativo que proponham modificações efetivas na realidade dos consumidores. Anos mais tarde, Almeida et al. (2018) ainda apontam a necessidade de mais estudos alinhados à TCR e principalmente reforçam a importância de 
que estes estudos busquem novos focos, com o objetivo de colaborarem no que tange à emancipação de consumidores vulneráveis. Como primeiro questionamento, a ser revertido em diretriz de pesquisa futura ao fim deste artigo, tem-se a validade e origem do rótulo de "consumidores vulneráveis". Amplamente utilizada em pesquisas alinhadas às TCRs (DANTAS et al., 2019), essa forma de denominar pessoas que são vistas como frágeis pelos agentes de marketing não parece fazer qualquer sentido quando se busca as lentes das Epistemologias do Sul. Isto porque, como será aprofundado na sessão quatro, essas pessoas/consumidores não são vulneráveis e sim vulnerabilizadas por sociedades de bases capitalistas, colonialistas e patriarcais. Tal visão crítica com relação à maneira como a vulnerabilidade vem sendo estudada em investigações de marketing alinha-se com as discussões do recente artigo de Silva et al. (2021).

Para Moore, Beazley e Maezler (1998), a reflexão autocrítica e o compromisso com a defesa dos direitos humanos constituem os alicerces para os estudos focados em consumidores em desvantagem mercadológica. Ozanne, Saatcioglu e Corus (2007) afirmam que a abordagem transformativa de pesquisa deve ter como principal foco a melhoria da vida dos pesquisados. Para Bettany e Burton (2006), adicionalmente, tais pesquisas devem buscar a emancipação dos sujeitos. Essa busca por emancipar consumidores é outra questão que pode ser discutida ao se buscar confluências entre a TCR e as Epistemologias do Sul. De acordo com a perspectiva das teses de Boaventura é necessário promover ecologia dos saberes para que todos sejam protagonistas de suas lutas e sujeitos que têm seus conhecimentos valorizados. Desta maneira, não faz sentido a ideia de alguém ser capaz de emancipar outra pessoa.

Para Mertens (2009), por mais que existam diferentes abordagens para os estudos que se proponham a seguir o paradigma da pesquisa transformativa, alguns pontos fundamentais devem distinguir tais esforços daqueles estudos alinhados às abordagens de pesquisa mais tradicionais:
(1) ênfase na vivência e nas experiências de grupos comumente deixados à margem; (2) busca do entendimento acerca de como e porque essa marginalização se reflete nas relações desiguais de poder; (3) foco na influência das forças governamentais e das demais forças sociais na manutenção dessa desigualdade.

No que diz respeito à metodologia, ainda que a TCR admita a utilização de métodos qualitativos, quantitativos e mistos, Deschenes (2007) e Ozanne, Saatcioglu e Corus (2007) apontam que metodologias qualitativas têm se mostrado mais adequadas para estudos associados à perspectiva transformativa por proporcionarem mais voz aos sujeitos de pesquisa.

A produção brasileira alinhada à TCR foi analisada por Almeida et al. (2018), que realizaram estudo levantando as pesquisas que seguiram a perspectiva transformativa desde 2005 até 2018. Segundo estes autores, as pesquisas nacionais abrangem poucas temáticas e não contemplam satisfatoriamente assuntos centrais como gênero, pobreza, sustentabilidade e saúde. Temas estes amplamente debatidos por autores alinhados com as Epistemologias do Sul, o que pode, mais uma vez, se configurar como uma oportunidade de caminho. Cabe o destaque de que a culpa por tal cenário não é somente dos autores e sim de toda a academia e suas estruturas como eventos e revistas científicas.

\section{Epistemologias do Sul: linhas abissais e opressões}

Para Boaventura de Sousa Santos, o capitalismo, o colonialismo e o patriarcado são capazes de produzir exclusões abissais, sendo estas caracterizadas pelo fato de a própria existência da pessoa ser suficiente para que esta seja oprimida. As Epistemologias do Sul têm a obrigação de transformar sujeitos ausentes em sujeitos presentes como condição imprescindível para identificar e aliar conhecimentos que podem contribuir para reinventar a emancipação e a libertação social (SANTOS, 2018). A característica fundamental do pensamento 
abissal, base para as críticas das Epistemologias do Sul, é a impossibilidade da copresença dos dois lados da linha. O universo "deste lado da linha" só prevalece na medida em que esgota o campo da realidade relevante: para além da linha há apenas inexistência, invisibilidade e ausência não dialética (SANTOS, 2007). Em outras palavras, as linhas abissais propostas por Boaventura de Sousa Santos nas Epistemologias do Sul separam as pessoas nos dois lados da linha, não havendo possibilidade de equivalência, ou de reciprocidade, uma vez que ocorre a caracterização de quem se encontra do outro lado da linha abissal como sub-humano (SANTOS, 2018).

Tal separação é tão relevante que influencia as pessoas até mesmo no que diz respeito ao acesso de serviços básicos, como os serviços de saúde. Neste sentido, Nunes e Louvison (2020) denunciam que é preciso enfrentar as dinâmicas capitalista, colonialista e patriarcal para que se tenha saúde coletiva de fato.

Torna-se fundamental pontuar que não há uma única maneira de não existência. São várias as lógicas e processos que produzem a não existência. Boaventura de Sousa Santos (2002) aponta cinco lógicas capazes de produzir a não existência: (1) monocultura do saber e do rigor do saber que dá conta de uma concepção de ciência moderna e de alta cultura que possuem critérios únicos de verdade e de qualidade estética respectivamente. A existência nesta lógica assume a forma de ignorância. A sociologia das ausências, também proposta por Boaventura, contribui para o rompimento com a monocultura do saber e evoca a ecologia dos saberes. A ignorância é ignorância de um certo saber, sendo assim a ecologia dos saberes é fundamental para que se rompa com a ideia de que existem saberes alternativos, que acabam por ser encarados com inferiores aos saberes "normais". A sociologia das ausências trabalha para que as não existências se tornem presentes. Sendo assim evidencia-se que a falta da experiência social é um desperdício criando condições para ampliar o campo das experiências críveis neste mundo e no momento presente; (2) monocultura do tempo linear que é a ideia de que a história tem sentido e direções, únicos e conhecidos. Esta lógica produz não existência declarando como atrasado o que é assimétrico em relação ao que é considerado avançado; (3) lógica da classificação social que consiste na naturalização da distribuição da população por categorias hierárquicas. A relação de dominação é vista assim como consequência e não causa da dominação; (4) lógica da escala dominante que na modernidade ocidental assume a forma de "universal e "global". Seguindo essa lógica as entidades ou realidades definidas como particulares ou locais são aprisionadas em escalas que as incapacitam de serem existências críveis ao que existe de forma universal ou global; (5) lógica da produtividade que assenta na monocultura dos critérios de produtividade capitalista. Esta lógica, segundo Boaventura de Sousa Santos, produz a não existência com base na improdutividade do trabalhador que é preguiçoso ou desqualificado profissionalmente. A autora do presente estudo defende que as cinco lógicas operam conjuntamente na produção da não existência de diversos consumidores vulnerabizados, ainda que esta última lógica seja a mais diretamente relacionada aos estudos na área de administração.

No que diz respeito a metodologias de pesquisa, o professor Boaventura de Sousa Santos em sua aula magistral intitulada "Metodologias pós-abissais: luta, experiência, corpo e autoria" ${ }^{2}$ enfatizou que as metodologias tradicionais podem ser usadas de modo contra-hegemônico para formular a sociologia das ausências, mas não são úteis para a sociologia das emergências. Nas palavras de Boaventura "o mais importante é conhecer com e não conhecer sobre, mas isso exige assumir riscos". No mesmo sentido, Cunha (2015)

\footnotetext{
2 Aula magistral "Metodologias pós-abissais: luta, experiência, corpo e autoria" do professor catedrático Boaventura de Sousa Santos, realizada no dia 12 de abril de 2019 no auditório da Faculdade de Economia da Universidade de Coimbra (FEUC).
} 
destaca que o primeiro passo para o reconhecimento e a quebra das exclusões promovidas pelas linhas abissais é a plena aceitação de que "o outro fala”. Para esta autora é preciso escutar e reconhecer como válidas as narrativas daqueles que são recorrentemente silenciados. Para Radvanskei e Silva (2020), somente por meio de pesquisas que tenham metodologias baseadas na ecologia de saberes é possível buscar combater as opressões. Estas indicações metodológicas parecem confluentes com as propostas de pesquisas qualitativas da TCR apontadas na sessão anterior. Ainda assim é preciso apontar que muitas pesquisas que dizem ter a TCR como base são, na prática, seguindo a corrente hegemônica de marketing, instrumentos de afirmação de supremacia do Norte com relação ao Sul.

Por fim, cabe o destaque de que as Epistemologias do Sul referem-se à produção e validação de conhecimentos fundamentados nas experiências de resistência e luta dos grupos sociais que passaram por injustiças e opressões derivadas do capitalismo, colonialismo e patriarcado. É um Sul epistemológico e não global. Dessa forma, o objetivo, de fato, dessa teoria é permitir que os grupos sociais oprimidos consigam representar o mundo em suas formas para, portanto, alcançarem suas próprias aspirações (BIDASECA; MENESES, 2018).

\section{Consumidores invisibilizados e explorados: vulneráveis ou vulnerabilizados?}

Tradicionalmente, a vulnerabilidade do consumidor pode ser definida como "um estado de impotência que emerge de um desequilíbrio nas interações ocorridas no ambiente de mercado ou a partir do consumo de produtos e mensagens mercadológicas" (BAKER; GENTRY; RITTENBURG, 2005, p. 134, tradução livre). Carneiro, Bellini e Pereira (2014, p. 5) designam como vulneráveis os consumidores "mais suscetíveis a sofrerem dano econômico, físico ou psicológico, ou como resultado de transações econômicas" devido a características que limitam sua capacidade de tomar decisões no mercado visando maximizar sua utilidade e seu bem-estar. Aqui cabe a ressalva de que esta visão coloca a culpa da vulnerabilidade no consumidor; a proposta deste ensaio teórico é provocar os pesquisadores para pensarem, sob a ótica das Epistemologias do Sul, se esta atribuição de culpa está correta ou se é possível culpabilizar as opressões sociais por seus efeitos nocivos nestas pessoas.

Voltando ao pensamento hegemônico, destaca-se que no parecer de Elms e Tinson (2012) e de Hamilton, Dunnett e Piacentini (2015), a vulnerabilidade do consumidor denota um fenômeno complexo relacionado com a ideia de consumidores negligenciados ou em desvantagem no mercado, enfocando variáveis como renda, raça, gênero e mobilidade, as quais resultam na exclusão de algumas pessoas no que tange à sua participação em atividades relacionadas ao consumo. Entretanto, os autores alertam para o fato de que, se as desigualdades econômicas e as circunstâncias espaciais podem ensejar a vulnerabilidade do consumidor, também por meio de normas e convenções sociais pode-se suscitar a vulnerabilidade, pois tais instâncias podem minar a capacidade de uma pessoa fazer valer seus direitos como consumidor.

A despeito do conforto e da segurança que os ambientes de mercado provêm para bilhões de pessoas, organizações e profissionais de marketing têm sido acusados - muitas vezes com razão, segundo Shultz e Holbrook (2009) - de explorar consumidores em geral e de tirar vantagens de alguns deles em particular, configurando-se uma íntima relação entre vulnerabilidade e oportunismo. A vulnerabilidade é igualmente associada por Diniz, Pereira e Bellini (2014) a questões de fragilidade do consumidor, de exiguidade de conhecimento quando o sujeito realiza uma transação, ou, ainda, a situações em que a pessoa pode estar desamparada em seu círculo familiar ou comunitário - circunstâncias que, frequentemente, independem de classe social.

Mason e Baker (2014) caracterizam então a vulnerabilidade no consumo como um estado existencial marcado pela impotência e falta de controle diante das condições sociais, culturais e/ou 
econômicas impostas pelo mercado. Para Baker, Gentry e Rittenburg (2005), trata-se de um fenômeno de curta duração que não configura uma situação estacionária para a maior parte dos consumidores; cabe o destaque de que esta afirmação não corresponde à realidade de milhões de consumidores colocados sem perspectiva de volta à margem da sociedade capitalista. Não obstante, Shultz e Holbrook (2009) questionam se, ao invés de eventualmente qualificar uma disfunção nas relações de mercado, a vulnerabilidade do consumidor não seria somente mais um doloroso artefato do sistema capitalista, ou mais um dentre os jogos de soma zero que tipificam o sistema socioeconômico. Esta última visão possui alguma indicação de aproximação com as Epistemologias do Sul ao colocar em xeque o papel do capitalismo no processo de vulnerabilização.

Ainda neste sentido, Woodliffe (2004) assevera que a vulnerabilidade do consumidor precisa ser encarada sob a perspectiva de que nem todos são iguais perante o mercado, enquanto Mansfield e Pinto (2008) afiançam que a vulnerabilidade pode se impor como duradoura para consumidores que apresentam certas características: (1) dificuldade ou impedimento de navegar pelos ambientes de mercado; (2) acesso reduzido a bens e serviços; (3) fragilidade ou debilidade física; ou (4) incapacidade de compreender adequadamente comunicações fraudulentas ou mensagens publicitárias.

De acordo com Mason e Pavia (2014), quando se aborda a vulnerabilidade no consumo, é usual considerar como vulnerável um indivíduo com capacidade limitada de se engajar efetivamente em relações de mercado. Essa vulnerabilidade pode advir de uma ampla gama de fatores pessoais e externos, mas o corpo e a saúde de um indivíduo podem ser catalisadores fundamentais para que alguém experimente a vulnerabilidade. As autoras ponderam que é por meio do corpo - esteja ele saudável ou desafiado por alguma condição de doença, idade avançada ou deficiência - que um indivíduo se engaja em práticas de consumo e construção identitária, as quais ocorrem em um ambiente de mercado dinâmico e estruturado a partir de processos e normas sociais capazes de potencializar a vulnerabilidade.

\section{Um convite para começar a pensar a exclusão na sociedade de consumo sob a perspectiva das Epistemologias do Sul: foco na opressão advinda da lógica capitalista}

Ao falar de uma das lógicas capazes de produzir a não existência, Boaventura de Sousa Santos (2002) destaca a "lógica produtivista" que assenta na monocultura dos critérios de produtividade capitalista. Esta lógica, segundo o autor, produz a não existência com base na improdutividade do trabalhador que é preguiçoso ou desqualificado profissionalmente. Santos (2007) invoca que uma concepção pós-abissal de marxismo pretende que a emancipação dos trabalhadores seja conquistada conjuntamente com a emancipação de todas as populações descartáveis do Sul global, que são oprimidas, mas não diretamente exploradas pelo capitalismo global. O mesmo autor reivindica que os direitos dos cidadãos não estarão seguros enquanto os não cidadãos sofrerem um tratamento sub-humano.

A não existência dessas pessoas fica ainda mais clara no caso de indivíduos que, além de não serem produtores, são considerados consumidores inadequados (FARIA, 2015), outra questão imperdoável de acordo com a monocultura capitalista (BAUMAN, 2008). Parte-se dessa discussão de não existência centrada na inadequação para produzir e para consumir na direção de pensar a exclusão na sociedade de consumo.

Para Castel (2011), o próprio conceito de exclusão já é problemático na medida em que se centra no indivíduo e não nas dinâmicas coletivas de dominação que estão em ação na sociedade. No presente estudo a exclusão social é vista como um fenômeno com fortes raízes na linha abissal demarcada pelo capitalismo. Para Boaventura de Sousa Santos o capitalismo, bem como o colonialismo e o patriarcado, é capaz de produzir exclusões abissais 
as quais se configuram pela degradação do indivíduo simplesmente pela sua própria existência.

A proposta aqui apresentada defende que a lógica capitalista tem papel fundamental na manutenção de alguns consumidores que na TCR seriam chamados de vulneráveis do lado não humano da linha abissal, produzindo assim a não existência dessas pessoas. Essa linha de raciocínio surge, de maneira sintética, do fato de que no capitalismo só tem existência corpos e mentes considerados capazes de serem produtores e/ou consumidores (BAUMAN, 2008; SANTOS, 2002). Um exemplo que pode ser usado para dar visibilidade ao que se está propondo, de maneira ainda muito incipiente neste momento, é o grupo composto por pessoas com diferentes tipos de deficiência. A discussão sobre o papel das pessoas com deficiência como produtoras é extremamente presente em estudos que denunciam, ainda que muitas vezes não de forma suficientemente crítica, as dificuldades que estas pessoas encontram para entrar no mercado de trabalho (FONTES, 2016; GIDRON, 2014; SANTOS; CARVALHO-FREITAS, 2018). Em síntese, apesar de apresentarem diversas facetas da importância das PcD serem vistas como potenciais trabalhadoras, é recorrente a observação de que a inclusão dessas pessoas no mercado de trabalho passa por tantas e diferentes barreiras que elas acabam não sendo consideradas elegíveis como produtoras (SANTOS, 2016). Diretamente, ainda que não somente, associado ao impedimento social de serem vistas como produtoras está o rótulo das pessoas com deficiência como não consumidoras. A visão simplista de que as pessoas com deficiência, especialmente as com deficiências intelectuais, não são capazes de ter renda é o primeiro alicerce para este rótulo (BAUMAN, 2008; McCLIMENS; HYDE, 2012). Resguarda-se a convicção de que as pessoas com deficiências precisam poder assumir o papel social de consumidores (BURNETT, 2006). No entanto, tal papel lhes é absolutamente negado pela sociedade de consumo que, em sua visão idealizada de mundo, não deixa espaço para nenhum tipo de fragilidade humana (ROCHA, 1995).
Em suma, o capitalismo mercantiliza os corpos (SANTOS, 2018) deixando de fora, na condição de não existência, corpos, que, segundo a própria lógica capitalista, não têm valor social. Poder-se-ia acrescentar aqui, além das pessoas com deficiência, os idosos, as pessoas com baixíssima renda (especialmente as que vivem abaixo da linha da pobreza), os analfabetos, entre outros. Wanderley (2008) apresenta que, por meio da intolerância perpetrada pelos dispositivos capitalistas de apartação, trata-se o segregado como um desigual, um não semelhante, um ser expulso não somente dos ambientes de produção e consumo, mas também do gênero humano. Adicionalmente, vale a ênfase na afirmação de Shildrick (2019) de que o neoliberalismo não tem em sua agenda a inclusão de corpos anômalos, assinalando que na sociedade do controle nada escapa ao impulso governamental para domesticar a diferença.

Cabe o destaque novamente de que não se acredita que da tríade capitalismo, colonialismo e patriarcado somente o primeiro seja capaz de fazer avançar as críticas que devem ser feitas com relação às pesquisas alinhadas à TCR. No que diz respeito ao patriarcado, por exemplo, muito se pode explorar a respeito da opressão vivenciada por consumidoras mulheres e por consumidores LGBT. Cunha (2015) lembra que a dominação do patriarcado é muito útil ao capitalismo, uma vez que manter as mulheres somente como procriadoras e mão de obra desprestigiada cria um exército de reserva enorme para os donos do capital. Além disso, no que se refere especificamente à opressão do patriarcado, no que tange ao consumo, muito se pode dizer sobre rótulos que são carregados pelas consumidoras as colocando em situação de vulnerabilidade simplesmente pelo fato de serem mulheres (HAMLIN; PETERS, 2018).

No que diz respeito ao colonialismo é fundamental enfatizar que as opressões causadas não estão no passado e de forma alguma se encerram com a "liberdade" das colônias. Vale lembrar que a missão colonial é a conquista não apenas de bens e de terras, mas especialmente das culturas e mentes 
dos seus habitantes. Nos espaços colonizados, os seus habitantes, subalternos oprimidos, não têm o direito à voz, a exprimir os seus saberes e a falar das suas realidades e experiências. As Epistemologias do Sul denunciam que a monocultura do saber resume o conhecimento válido ao que é produzido pelo Norte epistêmico, não conferindo ao conhecimento produzido no Sul colonizado o status de ciência válida (MENESES, 2018). Diante desse cenário, pesquisas alinhadas à perspectiva transformativa em marketing no Brasil tem um caminho importante no que diz respeito a vulnerabilidade de consumidores negros (ROCHA; CASOTTI, 2017) e indígenas (SILVA; KHUN JÚNIOR, 2018), além de ser urgente ter uma visão crítica a respeito de qual é a base teórica de construção de conhecimento na área.

\section{Proposta de diretrizes de pesquisa e considerações finais}

Abre-se esta última sessão com a afirmação de que para se engajar na proposta aqui apresentada é necessário que o pesquisador da área de marketing esteja realmente disposto a produzir estudos comprometidos com o aumento do bemestar dos consumidores. Além disto, é premissa de qualquer avanço que o conhecimento venha do Sul epistêmico, sendo necessário para isso um abandono da hegemonia do Norte que parece está muito distante de acontecer na área de marketing. Tanto no que diz respeito à TCR quanto às Epistemologias do Sul é recorrente a postura de oportunismo acadêmico. Alguns pesquisadores enquadram suas pesquisas nestas correntes, mas não tem a real intenção de se engajarem nas lutas de seus sujeitos de pesquisa. Uma prova básica desta situação são pesquisas que dizem utilizar a TCR, mas que sequer tem o grupo foco da pesquisa como sujeito com voz no campo. Em outras palavras, muitas vezes não é verdadeiro nem mesmo o "aprender sobre" o que faz o "aprender com" proposto nas Epistemologias do Sul, incrivelmente distante.
Ao pensar na análise da produção da TCR por meio das Epistemologias do Sul, a primeira questão fundamental é buscar entender verdadeiramente quem são os consumidores invisibilizados e quais recebem o rótulo de consumidores vulneráveis com o intuito, completamente deturpado, de compreender seus comportamentos e buscar nas suas fragilidades mais possibilidades de lucro empresarial. Ao buscar o conceito de linhas abissais este ensaio teórico propõe que os pesquisadores de marketing pensem no capitalismo, no colonialismo e no patriarcado como capazes de produzir a não existência e foquem seus estudos em temáticas relativas às opressões vividas por consumidores em decorrência dessas lógicas. Este foco nas pessoas que são consideradas sub-humanas, não dignas de validade cientifica de acordo com a as epistemologias dominantes, poderia ser um avanço significativo na relevância da produção nacional alinhada à TCR. Espera-se com os pontos levantados por meio deste ensaio teórico, e apresentados a seguir, propor caminhos iniciais no sentido de aproximar as pesquisas em marketing das Epistemologias do Sul.

Ressalta-se, entretanto, que, para além da escolha temática, os pesquisadores dispostos a seguir os caminhos da Epistemologia do Sul devem ter especial atenção aos procedimentos metodológicos. As metodologias pós-abissais pressupõem, acima de qualquer outro critério de rigor científico, que se deve construir conhecimento "com" e não "sobre". Ou seja, os sujeitos de pesquisa (como usualmente os pesquisadores se referem àqueles que são ouvidos nos estudos empíricos) são também autores da pesquisa na concepção de Boaventura de Sousa Santos. Uma vez que na maioria dos casos não se tem a liberdade de colocar esses sujeitos como coautores - o que na visão de Boaventura seria o ideal -, ao menos deve-se atentar para escolha de métodos de coleta e análise de dados que realmente sejam capazes de dar protagonismo aos participantes da pesquisa. Cabe também a ressalva de que nas pesquisas alinhadas às Epistemologias do Sul não há lugar para dar voz aos opressores, somente os oprimidos podem e devem ser ouvidos. 
Figura 1 - Análise crítica dos estudos alinhados à Transformative Consumer Research (TCR) com base nas Epistemologias do Sul.

1. O acadêmico deve ocupar lugar na luta, ou seja, torna-se militante nas lutas de seus sujeitos de pesquisa. Esse é um ponto fundamental para as Epistemologias do Sul e é completamente ignorado na TCR.

2. É urgente ajustar conceitos básicos como, por exemplo, definir os consumidores em situação de vulnerabilidade como "consumidores vulnerabilizados" e não como "consumidores vulneráveis", uma vez que a vulnerabilidade não é uma característica do consumidor e sim uma decorrência de processos sociais de exclusão. Tal ajuste, mesmo que pareça simples, tem o potencial de proporcionar a possibilidade de aproximação dos estudos da TCR com as Epistemologias do Sul.

3. Realizar estudos com foco no comportamento de consumidores vulnerabilizados que busquem as raízes dessa vulnerabilidade. Ao fazer tal mergulho com base nas Epistemologias do Sul um início promissor seria entender o papel do capitalismo, do colonialismo e do patriarcado em tais raízes.

4. Utilizar as opressões do capitalismo, colonialismo e patriarcado para identificar os que sofrem exclusões abissais e focar nesses indivíduos como consumidores vulnerabilizados. Tomando tal caminho, os consumidores vulnerabilizados passam a ser entendidos como pessoas que sofrem exclusões abissais.

5. Engendrar esforços de pesquisa motivados por finalidade aplicada e intervencionista. Nas Epistemologias do Sul o pesquisador tem que ter participação ativa.

6. Realizar estudos com foco no comportamento de mulheres como consumidoras que tenham como premissa a opressão por elas sofrida em decorrência do patriarcado.

7. Realizar estudos com foco no comportamento de pessoas LGBTQI+ como consumidoras que tenham como premissa a opressão por elas sofrida em decorrência do hetero-patriarcado.

8. Realizar estudos com foco no comportamento de índios e negros brasileiros como consumidores que tenham como premissa a opressão por eles sofrida em decorrência do colonialismo.

9. Realizar estudos com foco no comportamento de consumidores de baixa renda que tenham como premissa a opressão por eles sofrida em decorrência do capitalismo.

10. Ter como premissa básica que a lógica capitalista exclui corpos considerados por ela como improdutivos. Tal premissa é exatamente uma das lógicas de produção de não existência apresentadas nas Epistemologias do Sul.

11. Adotar postura crítica no que diz respeito aos agentes sociais que se beneficiam da manutenção de algumas pessoas como consumidoras vulnerabilizadas. Combater os opressores é uma das principais funções das Epistemologias do Sul.

12. É urgente que se promova a sociologia das emergências dando voz a consumidores recorrentemente silenciados nas pesquisas de marketing. Somente assim todas as promessas feitas pela TCR poderão ser perseguidas verdadeiramente.

13. Adotar metodologias capazes de dar voz aos oprimidos, e não aos opressores. Nas Epistemologias do Sul os opressores nunca devem ser ouvidos.

14. Construir referencial teórico que reflita a ecologia de saberes, que não traga somente autores do Norte epistêmico. As pesquisas de marketing, mesmo as que se dizem alinhadas com a TCR, não apresentam diversidade de ideias por meio de visões diversas de autores do Sul.

15. Discutir as exclusões abissais do ponto de vista de diversos enfoques na área de marketing: comportamento do consumidor, macromarketing, ética, marketing político, marketing de serviços públicos.

16. Não naturalizar as relações de poder existentes entre consumidores e organizações produtivas.

17. Incitar que os acadêmicos se comprometam a ter os oprimidos como coautores em suas pesquisas.

18. Utilizar o conceito de interseccionalidade, fundamental nas Epistemologias do Sul, de modo a buscar a complexidade das identidades sociais diante de múltiplas opressões.

Fonte: a autora. 
Os pontos levantados na Figura 1 não têm a intenção de esgotar as possibilidades de questões a serem levantadas a respeito das pesquisas alinhadas à TCR quando se tem a perspectiva das Epistemologias do Sul. Entende-se que existe um longo distanciamento entre o que é hoje realizado nas pesquisas em marketing e as propostas das Epistemologias do Sul. Sendo assim, diversas pesquisas futuras podem ser feitas no sentido de apontar caminhos para esta necessária, porém distante, relação entre a TCR e as propostas de Boaventura de Sousa Santos.

A principal contribuição desta pesquisa é exatamente levantar os pontos que as Epistemologias do Sul podem contribuir para que as pesquisas alinhadas à Transformative Consumer Research (TCR) de fato tenham o foco no bem-estar do consumidor. Por se tratar de um estudo exploratório, seu principal legado é exatamente lançar luz na referida questão e apontar possibilidade de caminhos futuros, como os que foram apresentados na Figura 1.

\section{Referências}

ALMEIDA, G.; ÁSSIMOS, B.; BATINGA, G.; PINTO, M. A abordagem Transformative Consumer Research (TCR): apontamentos paradigmáticos, discussões metodológicas e evolução das investigações internacionais e nacionais. In: ENCONTRO NACIONAL DA ANPAD, 42., 2018, Curitiba. Anais [...]. Curitiba: ANPAD, 2018.

BAKER, S.; GENTRY, J.; RITTENBURG, T. Building understanding of the domain of consumer vulnerability. Journal of Macromarketing, Chicago, v. 25, n. 2, p. 128-39, 2005.

BAUMAN, Z. Vida para consumo: a transformação das pessoas em mercadoria. Rio de Janeiro: Jorge Zahar, 2008.

BETTANY, S.; BURTON, L. Steps Towards Transformative Consumer Research Practice: A Taxonomy of Possible Reflexivities. Advances in Consumer Research, Columbus, v. 33, p. 227-234, 2006.
BIDASECA, K.; MENESES, M. P. Introdução: as epistemologias do sul como expressão de lutas epistemológicas e ontológicas. In: ANTONACCI, M. A.; BIDASECA, K.; FARIA, I. V.; SANTOS, B. S.; MARTIN, J. C. G.; MENESES, M. P.; NUNES, J. A RUFER, M.; MADROÑAL, A. C.; TOLOSA, J. R.; FERNANDES, D. K.; CASTILLO, R. A. H.; ARAUJO, S.; ANDRADE, O. A.; TZUL, G. T.; SILVA, T. C.; AVRITZER. L.; RAMOS. A. Epistemologias del Sur. Coimbra: Clacso. 2018. p. 11-21.

BURNETT, J. Disabled consumers: the use of the internet and attitudes toward web advertising. Journal of Advertising Research, New York, v. 46, n. 3, p. 1-24, 2006.

CARNEIRO, M.; BELLINI, C.; PEREIRA, R. Obsolescência programada e vulnerabilidade do consumidor na indústria de aparelhos de tecnologia móvel. In: ENCONTRO DA ASSOCIAÇÃO NACIONAL DE PÓS-GRADUAÇÃO E PESQUISA EM ADMINISTRAÇÃO, 38., 2014, Rio de Janeiro. Anais [...]. Rio de Janeiro: ANPAD, 2014.

CASTEL, R. As Armadilhas da exclusão. In: CASTEL, R.; WANDERLEY, L.; PAUGAM, S.; BELFIORE-WANDERLEY, M. Desigualdade e a questão social. São Paulo: Educ, 2011. p. 21-54.

CUNHA, T. Women in Power Women: outras economias criadas e lideradas por mulheres no sul não-imperial. Buenos Aires: Clacso, 2015.

DANTAS, B.; MORAES, T.; LEAL, J.; CAVALCANTI, H.; SILVA, B. A vulnerabilidade dos consumidores obesos na perspectiva da pesquisa transformativa do consumidor? In: ENCONTRO DA ASSOCIAÇÃO NACIONAL DE PÓS-GRADUAÇÃO E PESQUISA EM ADMINISTRAÇÃO, 43., 2019, São Paulo. Anais [...]. São Paulo: ANPAD, 2019.

DAVIS, B.; OZANNE, J. L.; HILL, R. P. The Transformative Consumer Research Movement. Journal of Public Policy \& Marketing, Chicago, v. 35, n. 2, 159-169, 2016.

DESCHENES, J. Behind Closed Doors: Reflecting on the Emotional Challenges of Doing Consumer Research on Painful Topics. Advances in Consumer Research, Columbus, v. 34, n. 1, p. 20-21, 2007. 
DINIZ, I.; PEREIRA, R.; BELLINI, C. Limitações digitais em adolescentes: um estudo sob a perspectiva da teoria da vulnerabilidade do consumidor. In: ENCONTRO DE MARKETING DA ANPAD, 6 ., 2014, Gramado. Anais [...] Gramado: ANPAD, 2014.

ELMS, J.; TINSON, J. Consumer vulnerability and the transformative potential of Internet shopping: An exploratory case study. Journal of Marketing Management, Chicago, v. 28, n. 11, p. 1354-1376, 2012.

FARIA, M. A eterna criança e as barreiras do ter: consumo de pessoas com Síndrome de Down e suas famílias. 2015. Tese (Doutorado em Administração) - Universidade Federal do Rio de Janeiro, Rio de Janeiro, 2015.

FONTES, F. Pessoas com Deficiência em Portugal. Lisboa: Fundação Francisco Manuel dos Santos, 2016.

GIDRON, B. Market-Oriented Social Enterprises Employing People with Disabilities: A Participants' Perspective. Journal of Social Entrepreneurship, Londres, v. 5, n. 1, p. 20-45, 2014.

HAMLIN, C.; PETERS, G. Consumindo como uma garota: subjetivação e empoderamento na publicidade voltada para mulheres. Lua Nova: Revista de Cultura e Política, São Paulo, n. 103, p. 167-202, 2018.

HAMILTON, K.; DUNNETT, S.; PIACENTINI, M. Introduction. In: DUNNETT, K. H. S.; PIACENTINI M. (ed.). Consumer vulnerability: conditions, contexts and characteristics. London: Routledge, 2015. p. 1-10.

MANSFIELD, P.; PINTO, M. Consumer vulnerability and credit card knowledge among developmentally disabled citizens. The Journal of Consumer Affairs, Hoboken, v. 42, n. 3, p. 425-438, 2008.

MASON, M.; BAKER, S. Beyond vulnerability: building resilient consumers and communities. Advances in Consumer Research, Columbus, v. 42, p. 7-11, 2014.

MASON, M.; PAVIA, T. Health and consumer vulnerability: identity dissolution and resiliency behaviors. Advances in Consumer Research, Columbus, v. 42, p. 7-11, 2014.
McCLIMENS, A.; HYDE, M. Intellectual disability, consumerism and identity: to have and have not? Journal of Intellectual Disabilities, Chicago, v. 16, n. 2, p. 135-144, 2012. Doi: https://doi. org/10.1177\%2F1744629512445844

MENESES, M. Colonialismo como violência: a "missão civilizadora" de Portugal em Moçambique. Revista Crítica de Ciências Sociais, Coimbra, 2018. Número especial. Doi: 10.4000/rccs.7741.

MERTENS, D. Research and evaluation in education and psychology: integrating diversity with quantitative, qualitative, and mixed methods. 3. ed. Los Angeles: Sage, 2009.

MERTENS, D. Transformative Paradigm: Mixed Methods and Social Justice. Journal of Mixed Methods Research, Los Angeles, v. 1, n. 3, p. 212225, 2007.

MICK, D. Meaning and mattering through transformative consumer research. Advances in Consumer Research, Columbus, v. 33, n. 1, p. 1-4, 2006.

MOORE, M.; BEAZLEY, S.; MAELZER, J. Researching disability issues. Buckingham: Open University Press, 1998.

NUNES, J.; LOUVISON, M. Epistemologias do Sul e descolonização da saúde: por uma ecologia de cuidados na saúde coletiva. Saúde e Sociedade, São Paulo, v. 29, n. 3, 2020.

OZANNE, J. Transformative Consumer Research: Creating Dialogical Spaces for Policy and Action Research. Journal of Public Policy \& Marketing, Chicago, v. 30, n. 1, p. 1-6, 2011.

OZANNE, J.; SAATCIOGLU, B.; CORUS, C. Participatory action research as engaged practice: implications for transformative consumer research. Advances in Consumer Research, Columbus, v. 34, n. 1, p. 21-22, 2007.

RADVANSKEI, I.; SILVA, M. Ecologia de saberes e perspectivismo: epistemologias decoloniais. Brazilian Journal of Development, São José dos Pinhais, v. 6, n. 10, p. 80801-80817, 2020.

ROCHA, A.; CASOTTI, L. Reflexões sobre o consumidor negro brasileiro. Revista Pensamento Contemporâneo em Administração, Rio de Janeiro, v. 11, n. 2, p. 47-62, 2017. 
ROCHA, E. Magia e capitalismo: um estudo antropológico da publicidade. 3. ed. São Paulo: Brasiliense, 1995.

SANTOS, B. O fim do império cognitivo. Coimbra: Almedina, 2018.

SANTOS, B. Para Além do Pensamento Abissal: das linhas globais a ecologia dos saberes. Novos Estudos CEBRAP, São Paulo, n. 79, p. 71-94, 2007. Doi: https://doi.org/10.1590/S0101-33002007000 300004

SANTOS, B. Para uma sociologia das ausências e uma sociologia das emergências. Revista Crítica de Ciências Sociais, Coimbra, n. 63, p. 237-280, 2002.

SANTOS, J. C.; CARVALHO-FREITAS, M. Sentidos do trabalho para pessoas com deficiência adquirida. Psicologia \& Sociedade, v. 30, p. 1-11, 2018. Doi: https://doi.org/10.1590/18070310/2018v30160054. Disponível em: https://bit. ly/3hHMY8h. Acesso em: 12 ago. 2020.

SANTOS, J. Representações sociais da deficiência intelectual e o processo de integração socioprofissional: análise exploratória com técnicos da área. 2016. Dissertação (Mestrado em Psicologia das Organizações e do Trabalho) - Universidade de Coimbra, Coimbra, 2016.

SHILDRICK, M. Dangerous discouses of disability, subjectivity and sexuality. London: Palgrave Macmillan, 2012.

SHULTZ, C.; HOLBROOK, M. The paradoxical relationships between marketing and vulnerability. Journal of Public Policy \& Marketing, Chicago, v. 28, n. 1, p. 124-127, 2009.

SILVA, R.; BARROS, D.; GOUVEIA, T.; MERABET, D. Uma discussão necessária sobre a vulnerabilidade do consumidor: avanços, lacunas e novas perspectivas. Cadernos EBAPE, Rio de Janeiro, v. 19, n. 1, p. 83-95, 2021. Doi: http://dx.doi. org/10.1590/1679-395120200026. Disponível em: https://bit.ly/3wmymAj. Acesso em: 12 jun. 2021.

SILVA, R.; KUHN JÚNIOR, N. Os meios de comunicação como fator de ressignificação da identidade indígena e da construção da memória da cultura mbyá-guarani - uma análise da tekoá yakã jú de Santo Ângelo/RS. Identidade! São Leopoldo v. 22, n. 2, p. 226-241, 2018.
WANDERLEY, M. Refletindo sobre a noção de exclusão. In: SAWAIA, B (org.). As artimanhas da exclusão: análise psicossocial e ética da desigualdade social. 8. ed. Petrópolis: Vozes, 2008. p. 17-26.

WOODLIFFE, L. Rethinking consumer disadvantage: the importance of qualitative research. International Journal of Retail \& Distribution Management, London, v. 32, n. 11, p. 523-531, 2004. 
Faria, M. D. 